\title{
Lutein-Loaded, Biotin-Decorated Polymeric Nanoparticles Enhance Lutein Uptake in Retinal Cells
}

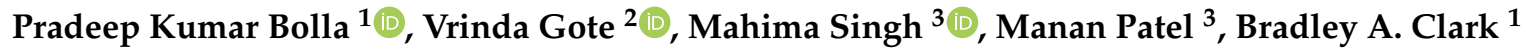 \\ and Jwala Renukuntla ${ }^{1, *}$ \\ 1 Department of Basic Pharmaceutical Sciences, Fred Wilson School of Pharmacy, High Point University, \\ High Point, NC 27262, USA; bollaniper@gmail.com (P.K.B.); bclark@highpoint.edu (B.A.C.) \\ 2 Division of Pharmacology and Pharmaceutical Sciences, School of Pharmacy, University of Missouri, \\ 2464 Charlotte Street, Kansas City, MO 64108, USA; vrindagote@mail.umkc.edu \\ 3 Department of Pharmaceutical Sciences, University of the Sciences in Philadelphia, \\ Philadelphia, PA 19104, USA; msingh@mail.usciences.edu (M.S.); mpatel@biolinkonline.com (M.P.) \\ * Correspondence: jrenukun@highpoint.edu; Tel.: +1-336-841-9729
}

Received: 28 July 2020; Accepted: 21 August 2020; Published: 24 August 2020

\begin{abstract}
Age related macular degeneration (AMD) is one of the leading causes of visual loss and is responsible for approximately $9 \%$ of global blindness. It is a progressive eye disorder seen in elderly people ( $>65$ years) mainly affecting the macula. Lutein, a carotenoid, is an antioxidant, and has shown neuroprotective properties in the retina. However, lutein has poor bioavailability owing to poor aqueous solubility. Drug delivery to the posterior segment of the eye is challenging due to the blood-retina barrier. Retinal pigment epithelium (RPE) expresses the sodium-dependent multivitamin transporter (SMVT) transport system which selectively uptakes biotin by active transport. In this study, we aimed to enhance lutein uptake into retinal cells using PLGA-PEG-biotin nanoparticles. Lutein loaded polymeric nanoparticles were prepared using $\mathrm{O} / \mathrm{W}$ solvent-evaporation method. Particle size and zeta potential (ZP) were determined using Malvern Zetasizer. Other characterizations included differential scanning calorimetry, FTIR, and in-vitro release studies. In-vitro uptake and cytotoxicity studies were conducted in ARPE-19 cells using flow cytometry and confocal microscopy. Lutein was successfully encapsulated into PLGA and PLGA-PEG-biotin nanoparticles $(<250 \mathrm{~nm})$ with uniform size distribution and high ZP. The entrapment efficiency of lutein was $\approx 56 \%$ and $\approx 75 \%$ for lutein-loaded PLGA and PLGA-PEG-biotin nanoparticles, respectively. FTIR and DSC confirmed encapsulation of lutein into nanoparticles. Cellular uptake studies in ARPE-19 cells confirmed a higher uptake of lutein with PLGA-PEG-biotin nanoparticles compared to PLGA nanoparticles and lutein alone. In vitro cytotoxicity results confirmed that the nanoparticles were safe, effective, and non-toxic. Findings from this study suggest that lutein-loaded PLGA-PEG-biotin nanoparticles can be potentially used for treatment of AMD for higher lutein uptake.
\end{abstract}

Keywords: lutein; PLGA; PLGA-PEG-biotin; ARPE-19; retina; macular edema; age-related macular degeneration; biotin-decorated nanoparticles; polymeric nanoparticles; targeted therapy

\section{Introduction}

The eye is considered as one of the most sophisticated sensory organs of the human body due to its intricate anatomical structure. Anatomically, the eye can be broadly classified into two segments; i.e., (a) the anterior segment comprising cornea, aqueous humor, conjunctiva, ciliary body, iris, and lens, and (b) the posterior segment consisting of sclera, choroid, Bruch's membrane, retinal pigment epithelium, retina, optic nerve, and vitreous humor [1,2]. All the components of the anterior and posterior segments co-ordinate functionally and enable vision formation [3]. Alterations in 
the arrangement of these structures due to several factors such as aging, infection, inflammation, exposure to UV light, injury, air pollution, and over/under secretion of ocular fluids result in ocular diseases. Based on the localization, the diseases can be categorized into diseases affecting the anterior segment (ocular pain and inflammation, allergic conjunctivitis, blepharitis, keratitis, sty, anterior uveitis, and glaucoma) [4] and posterior segment (macular edema (cystic and diabetic macular edema), retinitis, age-related macular degeneration (AMD), proliferative vitreoretinopathy, diabetic retinopathy, choroidal neovascularization, and others) [3]. AMD is one of the leading causes of visual loss and is responsible for approximately $9 \%$ of global blindness [5]. It is a progressive eye disorder common in the elderly population ( $>65$ years) mainly affecting the macula (central region of the retina) which is responsible for vision [6]. In 2012, it was estimated that 50 million people worldwide and 10 million people in the US suffered from AMD [6]. Till now, there was no clear understanding of the pathophysiology of AMD; however, it is a complicated disorder involving several risk factors which include smoking, UV light exposure, inflammation, and genetic factors [6-8]. The early stage of AMD is characterized by the deposition of yellowish deposits, known as soft drusen accumulations, in the retinal pigment epithelium and Bruch's membrane. The later stage of the disease is associated with loss of vision due to atrophy of photoreceptors and retinal pigment epithelium, retinal scarring, and detachment of retina [6,8]. If untreated, AMD is the leading cause of vision loss in $45 \%$ of all visual disability cases in the US alone [7]. Currently, there is no cure for AMD, and very few treatments such as anti-vascular endothelial growth factor (VEGF) have been proven to slow the progression of AMD. In addition, it is hypothesized that antioxidants and anti-inflammatory agents such as carotenoids (lutein, zeaxanthin, $\alpha$-carotene, $\beta$-carotene, lycopene, and $\beta$-cryptoxanthin) protect against AMD by absorbing UV light, reducing oxidative stress, and stabilizing cell membranes [9].

Lutein is a dihydroxy xanthophyll carotenoid ( $\beta, \varepsilon$-carotene-3, $3^{\prime}$-diol) and is ubiquitously available from a variety of green leafy vegetables, fruits, flowers, egg yolk, etc. [10,11]. Since humans/animals cannot synthesize lutein, it must be obtained from the diet. It has been reported in the literature that lutein intake has improved the visual acuity and prevented the progression on AMD [12]. In 2016, Allison et al. showed that lutein was selectively taken up by the retinal pigment epithelial cells and showed protection against oxidative stress induced damage [13,14]. In addition, a recently completed clinical study has also demonstrated the protective effects of lutein in early stage AMD. Thus, it is hypothesized that lutein supplementation could halt the progression of AMD by reducing the oxidative stress in the retina caused by hypoxia and intense exposure to UV light [6]. Unfortunately, lutein has poor bioavailability due to high lipophilicity $(\log$ P 7.9$)$ and poor aqueous solubility. $[15,16]$.

Management of ocular/ophthalmic diseases is mainly achieved by using conventional topical products such as ophthalmic solutions, suspensions, and ointments [17]. However, the bioavailability of drugs administered by these conventional drug delivery systems is very low, ranging from $1 \%$ to $5 \%$ for hydrophobic drugs and $<0.5 \%$ for hydrophilic drugs [17]. Drug delivery to the posterior part of the eye is challenging as the diseases affecting posterior segment require long-term delivery at a higher dose to the targeted tissues such as retina, choroid and Bruch's membrane. Moreover, treatment strategies such as oral, intraocular, and periocular routes have limited success due to the presence of static barriers such as sclera, retinal pigment epithelium (RPE), and multidrug resistance efflux pumps $[3,18]$. Various approaches have been explored in improving the ocular bioavailability, which include traditional formulation improvements, use of prodrugs, and carrier mediated drug transport. Formulation improvements include development of novel formulations such as suspensions, ointments, gels, nanoparticles, solutions, microemulsions, niosomes, liposomes, micelles, and others [1,2,17]. Transport of drugs, ions, and nutrients into and out of the ocular cell occurs mainly through transporters, receptors, and transmembrane proteins [19-21]. Transmembrane transporters/receptors are also involved in cellular processes such as absorption, distribution, and elimination of xenobiotics and nutrients [21,22]. Several transporters/receptors have been identified in the eye, which include glucose transporters, peptide transporters, amino acid transporters, nucleoside/nucleobase transporters, vitamin transporters, and nutrient receptors [21,22]. Various vitamin transporters have been characterized on 
the retinal epithelium which include folate, biotin, and ascorbic acid [20,22]. Transporter-mediated drug delivery can be achieved by conjugation of drug to a specific substrate/nutrient such as folic acid or biotin. The nutrient will be recognized by the transporter proteins and conjugated drug is translocated across the cell membrane thus increasing permeability [22].

Biotin (vitamin B7) is an essential water-soluble vitamin useful for cell growth, function, and development. It is a co-factor for several carboxylase enzymes which catalyze multiple metabolic reactions and acts as a regulator in cell signaling pathways and gene expression. Biotin cannot be synthesized in mammalian cells and therefore must be obtained from exogenous sources. Biotin transport in cells is mediated through sodium-dependent multivitamin transporter (SMVT) or biotin transporter. Biotin transporter is a high-affinity transporter involved in transport of biotin, whereas SMVT is a low-affinity transporter involved in the transport of biotin, pantothenic acid, and lipoic acid. It has been reported in the literature that SMVT is abundantly expressed in the blood-retina barrier and retinal cells (D407 cells). Thus, it is known that biotinylated prodrugs and polymeric nanoparticles utilize the SMVT and biotin transporters for enhanced permeability of drugs $[19,23]$. Moreover, scientists have reported that biotin-decorated polymeric nanoparticles have enhanced the uptake of poorly soluble drugs such as doxorubicin [24], SN-38 [25], and 15,16-dihydrotanshinone [26]. Therefore, we hypothesize that lutein-loaded PLGA-PEG-biotin polymeric nanoparticles can enhance the uptake of lutein into the retinal cells through SMVT transport system.

Polymeric nanoparticles are known to improve the bioavailability of drugs with poor biopharmaceutical properties $[27,28]$. Furthermore, polymeric nanoparticles have advantages, including biocompatibility, enhanced stability, sustained release, and improved efficacy [28-32]. Polymeric nanoparticles are prepared using biodegradable polymers such as poly(lactide co-glycolide) (PLGA), gelatin, chitosan, albumin, alginate polycaprolactone, polyglycolides, poly (methyl methacrylate), and polyethylene glycol (PEG) [28,33]. Previously, lutein was encapsulated into several nanocarriers, such as PLGA nanoparticles, liposomes, nanoemulsions, nanocrystals, lipid nanocapsules, and nanodispersions [34-40]. In the present study we aimed to prepare and characterize lutein-loaded polymeric nanoparticles (PLGA and PLGA-PEG-biotin) and evaluate their enhanced uptake in retinal cells.

\section{Materials and Methods}

\subsection{Materials}

Lutein $(90 \%)$ was purchased from Acros Organics (Fair Lawn, NJ, USA). Dimethyl sulfoxide (DMSO), methanol (HPLC grade), tetrahydrofuran (HPLC grade), dichloromethane, sodium chloride, disodium hydrogen phosphate, potassium dihydrogen phosphate, MTT (3-(4,5-dimethylthiazol2-yl)-2,5-diphenyltetrazolium bromide), and ammonium chloride $\left(\mathrm{NH}_{4} \mathrm{Cl}\right)$ were purchased from Fisher Scientific (Fair Lawn, NJ, USA). Sodium dodecyl sulphate (SDS) and polyvinyl alcohol (PVA: MW: 30,000-70,000) were procured from Sigma Aldrich (St. Louis, MO, USA). PLGA (50:50; Mw: 10,000 Da) and PLGA-PEG-biotin (50:50; Mw: 10,000 Da-2000 Da) were purchased from Akina PolySciTech, Inc, West Lafayette, IN, USA. Dulbecco's modified Eagle medium (DMEM, Gibco's), Dulbecco's phosphate-buffered saline (DPBS), Triton-X, and trypsin (TrypLE, Gibco) were purchased from Thermo Fisher Scientific (Fair Lawn, NJ, USA). Cellulose ester dialysis tubing (Biotech grade; Mw: $300 \mathrm{kDa}$ ) was procured from Spectrum Laboratories, Inc (Gardena, CA, USA). Fluorescein isothiocyanate (FITC) and 4',6-diamidino-2-Phenylindole (DAPI) were purchased from Invitrogen, Labelling and Detection, Molecular Probes, ThermoFisher Scientific, (Fair Lawn, NJ, USA). Human retinal pigment epithelial cell line (ARPE-19) was purchased from American Type Culture Collection (ATCC, Manassas, VA, USA). 


\subsection{Methods}

\subsubsection{Preparation of Lutein-Loaded Polymeric Nanoparticles}

Lutein-loaded polymeric nanoparticles were prepared using the oil-in-water $(\mathrm{O} / \mathrm{W})$ emulsion solvent evaporation method reported earlier with slight modifications (Figure 1) [41,42]. In brief, $100 \mathrm{mg}$ of polymer (PLGA or PLGA-PEG-biotin) was dissolved in $5 \mathrm{~mL}$ of dichloromethane and lutein (20 mg) was dissolved in $2 \mathrm{~mL}$ dichloromethane separately. The polymer and lutein solutions were mixed to form a homogenous organic phase. The organic phase was sonicated in a bath sonicator for $5 \mathrm{~min}$ followed by slow addition to an aqueous solution of $2 \%$ PVA (20 mL) under continuous stirring on a magnetic stirrer. The resultant mixture was sonicated at $30 \%$ amplitude for 5 min using a probe sonicator (Fisher Scientific ${ }^{\mathrm{TM}}$ Model 505 Sonic Dismembrator) to obtain an emulsion. The sonication step was performed in an icebath to prevent overheating of the emulsion. After sonication, the emulsion was stirred gently at room temperature overnight until complete evaporation of dichloromethane. Un-entrapped lutein and PVA residue were removed from the emulsion by washing three times with deionized water using Hitachi ultracentrifuge at 22,000× $g$ for $1 \mathrm{~h}$. Finally, the nanoparticles formed were lyophilized using laboratory freeze dryer (Harvestright, Salt Lake City, UT, USA) for 24 h.

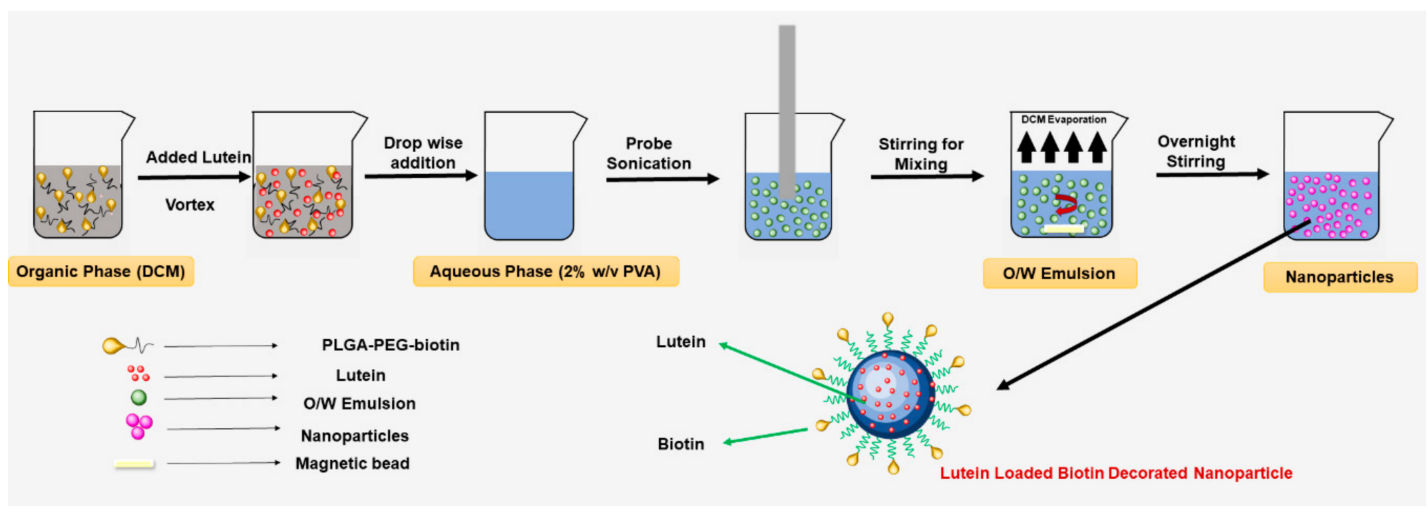

Figure 1. Schematic representation of oil in water emulsion-solvent evaporation method for preparation of lutein loaded PLGA-PEG-biotin nanoparticles.

\subsubsection{Determination of Size, Polydispersity Index, and Zeta Potential}

The particle size, polydispersity index (PDI), and zeta-potential (ZP) of lutein-loaded PLGA and PLGA-PEG-biotin nanoparticles were measured using the dynamic light scattering (DLS) technique. The nanoparticles $(200 \mu \mathrm{L})$ were dispersed in $10 \mathrm{~mL}$ of double distilled de-ionized water and measurements were determined using Malvern Zetasizer Nano ZS90 (Malvern Instruments, Malvern, $\mathrm{UK})$ at $25^{\circ} \mathrm{C}$. All the measurements were performed in triplicate $(\mathrm{n}=3)$.

\subsubsection{Lutein Quantification Using HPLC}

The amount of lutein in the samples was quantified using Waters Alliance e2695 HPLC (Waters Corporation, Milford, MA, USA) equipped with 2996 photodiode array (PDA) detector and Empower 2.0 software. The analysis was performed using reverse-phase Waters ${ }^{\circledR} \mathrm{C}-18$ column $(5 \mu \mathrm{m} ; 250 \mathrm{~mm} \times 4.6 \mathrm{~mm})$ under isocratic conditions (flow rate of $1 \mathrm{~mL} / \mathrm{min}$ at $25^{\circ} \mathrm{C}$ ). Mobile phase was a mixture (90:10) of methanol and tetrahydrofuran. The analyte was monitored at $450 \mathrm{~nm}$. Sample injection volume was $20 \mu \mathrm{L}$ and the run time was $10 \mathrm{~min}$. Retention time of lutein was $3.85 \mathrm{~min}$ [43]. All the samples injected were filtered through $0.45 \mu \mathrm{m}$ membrane filter. Stock solution $(1 \mathrm{mg} / \mathrm{mL})$ of lutein was prepared in the mobile phase, and calibration standards $(\mathrm{n}=3)$ ranging from $(1 \mu \mathrm{g} / \mathrm{mL}$ to $100 \mu \mathrm{g} / \mathrm{mL})$ were serially diluted in the mobile phase. Similar standard curve was also prepared by dissolving lutein in DMSO. Calibration curves were obtained by plotting peak area against 
the concentration of lutein. The lutein content in the samples was determined quantitatively using the linear regression equations from the calibration curves $\left(\mathrm{R}^{2}>0.99\right)$. The HPLC method provided rapid and reproducible results without a significant difference in intra and inter-day analysis.

\subsubsection{Determination of Lutein Encapsulation Efficiency (\%EE) and Drug Loading (\%DL)}

The encapsulation and loading of lutein into nanoparticles were determined by quantifying the lutein content in freeze dried nanoparticles using HPLC. In brief, the freeze-dried nanoparticles (10 mg) were dissolved in $10 \mathrm{~mL}$ DMSO and the amount of lutein was determined using HPLC. The $\% E E$ and \%DL of lutein in the nanoparticles were determined using the following formulae (Equations (1) and (2)). All the measurements were performed on three different samples $(n=3)$.

$$
\begin{gathered}
\% \mathrm{EE}=(\text { Amount of lutein remained in nanoparticles }) /(\text { Initial amount of lutein }) \times 100 \\
\% \mathrm{DL}=(\text { Weight of lutein in nanoparticles }) /(\text { Weight of polymer used }) \times 100
\end{gathered}
$$

\subsubsection{Differential Scanning Calorimetry (DSC)}

Interaction of lutein with PLGA and PLGA-PEG-biotin was confirmed using DSC technique. Calorimetric analysis was performed for lutein, PVA, polymers (PLGA and PLGA-PEG-biotin), and lutein-loaded polymeric nanoparticles using a DSC822e (Mettler Toledo, Columbus, OH, USA) instrument. Samples (3-11 mg) were accurately weighed in aluminum pans ( $40 \mu \mathrm{L}$ capacity) and were hermetically sealed using a crimping device. The reference standard was an empty aluminum pan. Nitrogen was purged at a rate of $20 \mathrm{~mL} / \mathrm{min}$ during the analysis. Samples were held isothermally at $25{ }^{\circ} \mathrm{C}$ for $5 \mathrm{~min}$ and then heated at $10{ }^{\circ} \mathrm{C} / \mathrm{min}$ to $280^{\circ} \mathrm{C}$. All the thermograms recorded were analyzed using STARe software.

\subsubsection{Fourier Transform Infrared Spectroscopy (FTIR)}

A JASCO-FT/IR 4600 instrument (Jasco instruments, Easton, MD, USA) using the attenuated total reflection (ATR) technique was used to record the FTIR spectra of lutein, PVA, polymers (PLGA and PLGA-PEG-biotin), and lutein-loaded polymeric nanoparticles. The sample compartment was flushed with argon prior to each run. Each sample was ground to fine powder with a KBr pellet. The scanning range was from 500-4000 $\mathrm{cm}^{-1}$. After measurement of the spectrum, data were analyzed and plotted. Carbon dioxide $\left(\mathrm{CO}_{2}\right)$ and water $\left(\mathrm{H}_{2} \mathrm{O}\right)$ peaks were subtracted from the original spectrum to obtain the final IR spectrum.

\subsubsection{In-Vitro Release Studies}

Drug release behavior from lutein-loaded polymeric nanoparticles was determined using the dialysis bag method (MWCO: $300 \mathrm{kDa}$ ) [27]. Initially, several release media were screened to determine the solubility of lutein. Phosphate-buffered saline $(\mathrm{pH} 7.4)$ with $0.2 \% w / v$ sodium dodecyl sulphate was chosen as the suitable release medium for release studies to maintain sink conditions (saturation solubility: $40.1 \pm 8.47 \mu \mathrm{g} / \mathrm{mL}$ ) [10]. After selecting the release medium, $1 \mathrm{~mL}$ lutein-loaded polymeric nanoparticles $(\approx 1 \mathrm{mg}$ lutein) were transferred to individual dialysis tubing and release medium $(1 \mathrm{~mL})$ was added to each tubing. Leakage was prevented by sealing the tubing tightly at both ends. Sealed dialysis tubings loaded with nanoparticles were transferred to $250 \mathrm{~mL}$ beakers containing $100 \mathrm{~mL}$ of release medium in a shaking water bath $(100 \mathrm{rpm})$ (maintained at $37 \pm 0.5{ }^{\circ} \mathrm{C}$ ). To prevent any evaporation of release medium, beakers were tightly sealed with parafilm. At a pre-determined time-intervals $(0.5,1,2,3,4,5,6,7,8$, and $24 \mathrm{~h})$, samples $(10 \mathrm{~mL})$ were collected from each beaker and replaced with $10 \mathrm{~mL}$ of fresh release medium. The cumulative amount of drug released from the formulations was quantified using UV spectrophotometer (6405 UV/Vis Spectrophotometer, Jenway, Staffordshire, UK) by measuring the absorbance at $\lambda_{\max }$ of $440 \mathrm{~nm}$ at different timepoints. All experiments were performed on three different samples $(n=3)$. 


\subsubsection{Cell Culture Studies}

\section{Cell Culture}

ARPE-19 cells were used to determine the in-vitro cellular uptake and cytotoxicity of lutein and lutein-loaded polymeric nanoparticles (PLGA and PLGA-PEG-biotin). ARPE-19 cells were purchased from American Type Culture Collection and stored in liquid nitrogen. The cells were cultured in DMEM/ F-12 (1:1 ratio) media containing 10\% (v/v) heat-inactivated fetal bovine serum (FBS), $100 \mathrm{U} / \mathrm{mL}$ penicillin, $100 \mu \mathrm{g} / \mathrm{mL}$ streptomycin, $1 \%(v / v)$ MEM non-essential amino acids, and $1 \%$ sodium bicarbonate. The cells were grown in T-75 Corning flasks and incubated at $37^{\circ} \mathrm{C}, 5 \% \mathrm{CO}_{2}$, and $95 \%$ relative humidity and harvested at $80-90 \%$ confluency.

\section{FITC Labelling}

The in-vitro cellular uptake levels of lutein-loaded PLGA and PLGA-PEG-biotin nanoparticles, and lutein alone were determined by labeling (surface adsorption) the samples with FITC, which is widely used to label proteins [44], drugs [45], and polymers [46]. FITC labelling was performed according to a previously reported protocol with slight modifications [47]. In brief, $10 \mu \mathrm{g}$ of lyophilized nanoparticles (PLGA or PLGA-PEG-biotin) were suspended in $50 \mathrm{mM}$ phosphate buffered saline $(1 \mathrm{~mL})$ to make a $10 \mu \mathrm{g} / \mathrm{mL}$ of nanoparticle suspension. Separately, FITC was powdered and dissolved in DMSO $(1 \mathrm{mg} / \mathrm{mL})$ since FITC was not soluble in water. The FITC solution was added to nanoparticle suspension and incubated in the dark for $12 \mathrm{~h}$ at $4{ }^{\circ} \mathrm{C}$. After incubation, $1 \mathrm{~mL}$ of $50 \mathrm{mM} \mathrm{NH}_{4} \mathrm{Cl}$ was added to the mixture to inactivate unreacted FITC. Further, the FITC labelled polymeric nanoparticles were subjected to dialysis to remove any unreacted FITC and $\mathrm{NH}_{4} \mathrm{Cl}$. Finally, the FITC-labelled nanoparticles were filtered through a $0.22 \mu \mathrm{m}$ nylon filter to ensure sterility. The samples were aliquoted and stored at $-20^{\circ} \mathrm{C}$ until further use. The sample for FITC-labelled lutein was prepared in a similar way as described above, except lutein was dissolved in DMSO $(5 \mathrm{mg} / \mathrm{mL})$ and then mixed with FITC solution.

In Vitro Cellular Uptake Studies Using Flow Cytometry (Fluorescence-Activated Cell Sorting (FACS))

Intracellular uptake of FITC-labelled nanoparticles and lutein alone in ARPE-19 cells was determined by incubating the cells and then evaluating time-dependent uptake using flow cytometry (FACS). ARPE-19 cells were seeded in a 12-well plate at a density of $0.5 \times 10^{6}$ cells/ well with $1 \mathrm{~mL}$ of complete DMEM/F-12 media. The cells were treated with $10 \mu \mathrm{L}$ of each sample which included control (DMSO), FITC-lutein, FITC-lutein PLGA nanoparticles, and FITC-lutein PLGA-PEG-biotin nanoparticles. Then, the treated cells were incubated for various times $(3,6,9$, and $12 \mathrm{~h})$. At each time point, the media was removed from the wells and the cells were harvested by using $200 \mu \mathrm{L}$ of trypsin (TrypLE, Gibco). This was followed by $5 \mathrm{~min}$ incubation and addition of serum containing DMEM/F-12 media. Further, the cells were collected in FACS tubes and centrifuged at 20,000 rpm for $5 \mathrm{~min}$ to obtain a cell pellet. The media was then discarded, and the cells were washed twice using $1 \mathrm{~mL}$ of (DPBS). The final sample was prepared in DPBS and acquired by flow cytometry to determine the mean FITC fluorescence intensity of the cells at an excitation wavelength of $490 \mathrm{~nm}$. The mean FITC fluorescence intensity values obtained for all the samples $(n=3)$ were plotted using bar-graphs in GraphPad Prism (version 5.0) and the differences were observed.

\section{In Vitro Cellular Uptake Studies Using Confocal Laser Scanning Microscopy}

Intracellular distribution of FITC-labelled polymeric nanoparticles (PLGA and PLGA-PEG-biotin) in ARPE-19 cells was determined using confocal laser scanning microscopy (CLSM). FITC-lutein-PLGA-PEG-biotin nanoparticles, FITC-lutein PLGA nanoparticles and FITC-lutein were prepared using the same method described in earlier sections. The cells were seeded in an 8-chamber confocal microscopy slide precoated with collagen (Nunc Lab-Tek, Thermo Fisher Scientific, Waltham, MA, USA) with $200 \mu \mathrm{L}$ of complete DMEM/F-12 media. This was followed by $10 \mu \mathrm{L}$ 
additions of various treatment samples which included control (DMSO), FITC-lutein, FITC-lutein PLGA nanoparticles, and FITC-lutein PLGA-Peg-biotin nanoparticles into each chamber of the 8-chamber plate. Further, the treatment groups were incubated for 6 and $12 \mathrm{~h}$. At each time point, the culture media was removed, and the cells were washed two times on a shaker with $300 \mu \mathrm{L}$ of DPBS for $5 \mathrm{~min}$. This was followed by fixing the cells with freshly prepared cold $4 \%$ buffered paraformaldehyde solution $(200 \mu \mathrm{L})$ and incubating at $37^{\circ} \mathrm{C}$ for $20 \mathrm{~min}$. After incubation, the fixing solution was removed, and the cells were washed again using $300 \mu \mathrm{L}$ DPBS ( 3 times $\times 5$ min each). Further, the nuclei of the cells were stained with $100 \mu \mathrm{L}$ of DAPI (working solution of $10 \mu \mathrm{g} / \mathrm{mL}$ ) for $15 \mathrm{~min}$ in dark. The cells were then mounted and sealed with cover slip to prevent any evaporation of mounting media and dehydration of the cells. The ARPE- 19 cell slides were stored at $4{ }^{\circ} \mathrm{C}$ before the actual analysis. A Leica Confocal Laser Scanning Microscope (Leica TCS SP5, Wetzlar, Germany) was used to analyze the cells for green fluorescence-FITC and blue fluorescence-DAPI.

In Vitro Cell Viability Studies (MTT Assay)

Cellular cytotoxicity of lutein PLGA-PEG-biotin nanoparticles, lutein PLGA nanoparticles and lutein alone were determined in ARPE-19 cells by using MTT (3-(4,5-dimethylthiazol-2-yl)2,5-diphenyltetrazolium bromide) assay. MTT is a yellow tetrazole dye which is reduced to purple formazan crystals by viable or living cells. The cell viability is determined by measuring the absorbance. ARPE-19 cells were seeded at a density of $1 \times 10^{4}$ cells in a 96-well plate. The cells were supplemented with $200 \mu \mathrm{L}$ of DMEM/ F-12 culture media (1:1 ratio) containing 10\% fetal bovine serum. The samples (lutein-PLGA-PEG-biotin nanoparticles, lutein-PLGA nanoparticles. and lutein) were prepared in serum free DMEM: F-12 media and filtered through a $0.22 \mu \mathrm{m}$ nylon filter. A small quantity of dichloromethane $(200 \mathrm{uL})$ was added to dissolve lutein in the media. Complete DMEM/F-12 from the cell lines was replaced with $100 \mu \mathrm{L}$ solution of treatment samples prepared in serum free media. All the three treatment groups were analyzed at four concentrations which included 10, 20, and $50 \mu \mathrm{g} / \mathrm{mL}$ of equivalent lutein. The cells were incubated with each sample for $24 \mathrm{~h}$ at $5 \% \mathrm{CO}_{2}$ and $37^{\circ} \mathrm{C}$. After incubation, the cells were washed twice with PBS. Separately, MTT reagent A and MTT reagent $B$ were mixed in the ratio 100:1 to make a stock solution of the dye. Further, $20 \mu \mathrm{L}$ of MTT stock solution was added to each well and incubated for $3.5 \mathrm{~h}$. Finally, the absorbance of formazan solution was measured using a microplate reader (BioRad, Hercules, CA, USA) at an excitation wavelength of $485 \mathrm{~nm}$. Five percent Triton-X prepared in serum free media served as the positive control and serum free media lacking any samples served as the negative control. Cell viability was calculated according to the formula (Equation (3)).

$\%$ Cell Viability $=($ Absorbance of sample-absorbance of negative control $) /$

(Absorbance of positive control-absorbance of negative control) $\times 100$

\subsubsection{Statistical Analysis}

Statistical analysis was performed using GraphPad Prism ${ }^{\circledR}$ software (Version 5.0, San Diego, CA, USA). A non-parametric $t$-test followed by Bonferroni's multiple comparison post-test was used to compare cellular uptake of nano-formulations.

\section{Results and Discussion}

\subsection{Determination of Particle Size, PDI, and ZP}

The size, PDI, and ZP of lutein-loaded polymeric nanoparticles are provided in Table 1. Results show that all the lutein-loaded nanoparticles had sizes of $<250 \mathrm{~nm}$. The sizes of lutein-loaded PLGA and PLGA-PEG-biotin nanoparticles were $196.4 \pm 20.04 \mathrm{~nm}$ and $208.0 \pm 3.38 \mathrm{~nm}$, respectively. Figure 2 confirms the monodisperse distribution of nanoparticles for both formulations. Zeta potential results revealed that lutein-loaded PLGA-PEG-biotin nanoparticles had higher 
$\mathrm{ZP}$ values $(-27.2 \pm 2.04 \mathrm{mV})$ compared to lutein-loaded PLGA nanoparticles $(-11.2 \pm 2.12 \mathrm{mV})$. The shift of ZP values towards higher negativity could be due to the presence of terminal carboxylic groups in the PEG-biotin portion of block polymer. In addition, negative ZP values result in higher stability of nanoparticles due to prevention of non-specific interaction with proteins in biological proteins. PLGA-based polymers were chosen for this study due to unique properties which include biocompatibility, targetability, biodegradability, and versatile biodegradation kinetics. Peroxisomal degradation of PLGA-based polymers will result in the formation of safe degradation products such as lactic acid and glycolic acid, which are removed by the Kreb's cycle [48]. However, due to the hydrophobic nature of PLGA, the nanoparticles are rapidly cleared by the mononuclear phagocyte system using opsonization process. Therefore, coating with hydrophilic polymers such as PEG could bypass the opsonization process due to steric repulsion forces. This results in enhancing the bioavailability and half-lives of the drugs by increasing the circulation time of nanoparticles in the plasma [48,49]. Moreover, all the polymers (PLGA, PLGA-PEG-biotin, PVA) are approved by USFDA as inactive ingredients in various formulations [50].

Table 1. Size, polydispersity index (PDI), zeta-potential (ZP), and encapsulation efficiency (\%EE) of lutein-loaded PLGA and PLGA-PEG-biotin nanoparticles $(n=3)$. Data are represented as means \pm standard deviations (SDs).

\begin{tabular}{cccccc}
\hline S.no & Particle Type & Size (nm) & PDI & ZP (mV) & EE (\%) \\
\hline 1 & Lutein PLGA & $196.4 \pm 20.04$ & $0.087 \pm 0.016$ & $-11.12 \pm 2.12$ & $56.05 \pm 7.28$ \\
2 & Lutein PLGA-PEG-biotin & $208.0 \pm 3.38$ & $0.206 \pm 0.016$ & $-27.2 \pm 2.04$ & $74.56 \pm 10.25$ \\
\hline
\end{tabular}

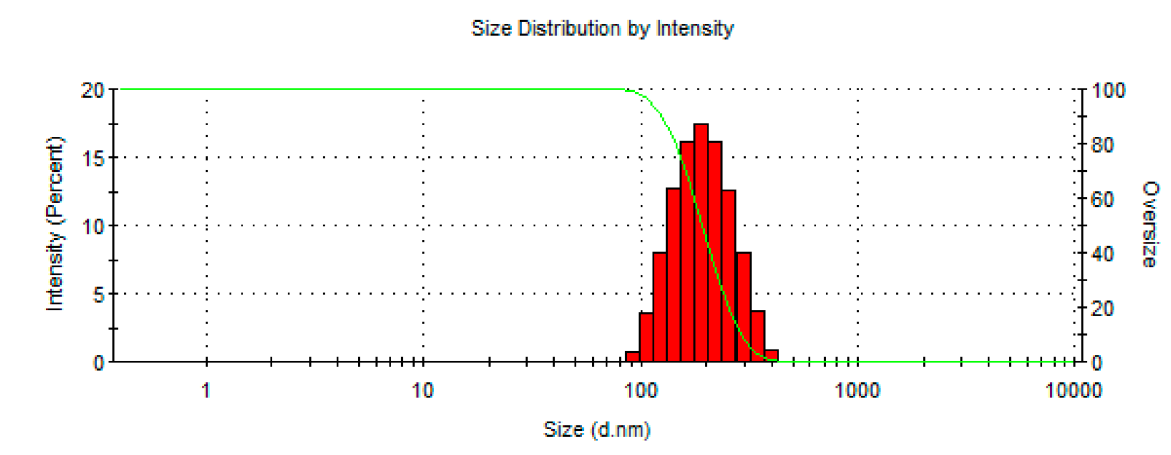

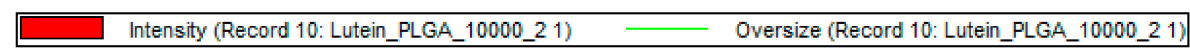

(a)

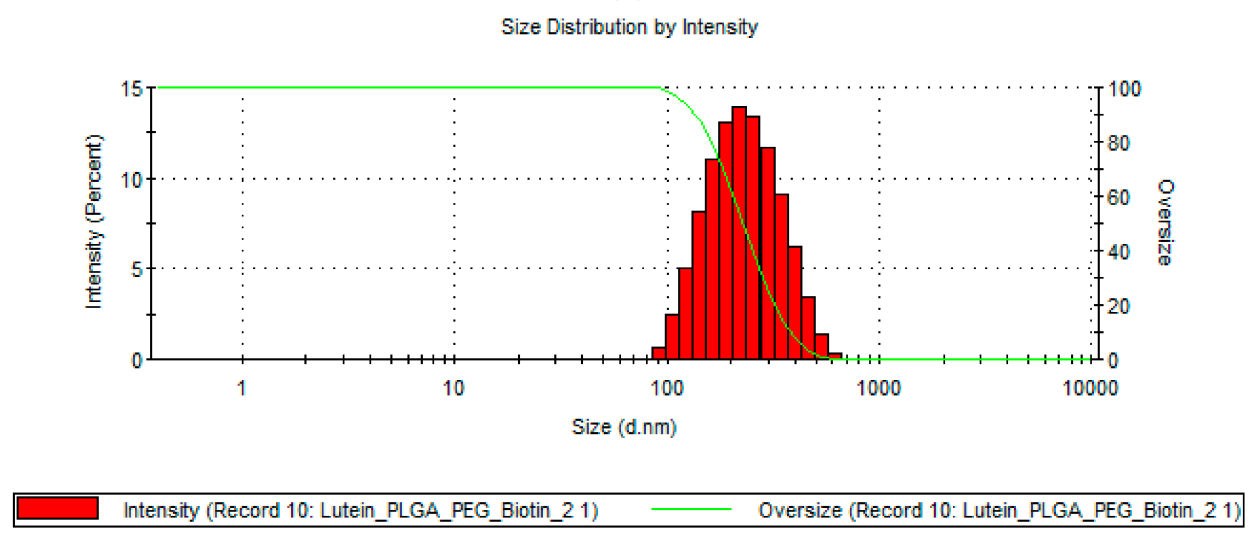

(b)

Figure 2. Size distribution curves of (a) lutein-PLGA nanoparticles and (b) lutein PLGA-PEGbiotin nanoparticles. 


\subsection{Determination of Encapsulation Efficiency (\%EE) and Drug Loading (\%DL)}

Results showed that PLGA-PEG-biotin polymer had greater lutein encapsulation compared with the PLGA polymer. The entrapment of lutein values were $56.05 \% \pm 7.28 \%$ and $74.56 \% \pm 10.25 \%$ for lutein PLGA and PLGA-PEG-biotin nanoparticles, respectively. The lutein loading values in PLGA and PLGA-PEG-biotin nanoparticles were $\approx 11.2 \%$ and $\approx 14.9 \%$, respectively (Table 1 ).

\subsection{DSC}

DSC is a widely used technique to confirm the polymorphic changes of drugs and polymers in formulation research. Thermograms of lutein, polymers, PVA, and lutein-loaded nanoparticles are provided in Figure 3. Results show that lutein has sharp characteristic endothermic peaks at $64.07^{\circ} \mathrm{C}$ and $58.15^{\circ} \mathrm{C}$. In addition, PLGA had a small endothermic peak at $45.28^{\circ} \mathrm{C}$. There was no specific peak/melting point observed for PLGA-PEG-biotin and PVA, suggesting their amorphous nature. The characteristic endothermic peak of lutein disappeared in thermograms of lutein-loaded polymeric nanoparticles, suggesting that lutein was rendered amorphous by its interaction with the polymer. The transformation of lutein from crystalline to amorphous form is important, as amorphous forms are characterized by higher solubilities and increased bioavailability [51-54]. Similar results (loss of characteristic peak) were observed in other studies where crystalline drugs such as SN-38, doxorubicin oxcarbazepine, prilocaine, and adefovir were encapsulated into PLGA-based micro- and nanoparticles $[24,25,55-57]$.

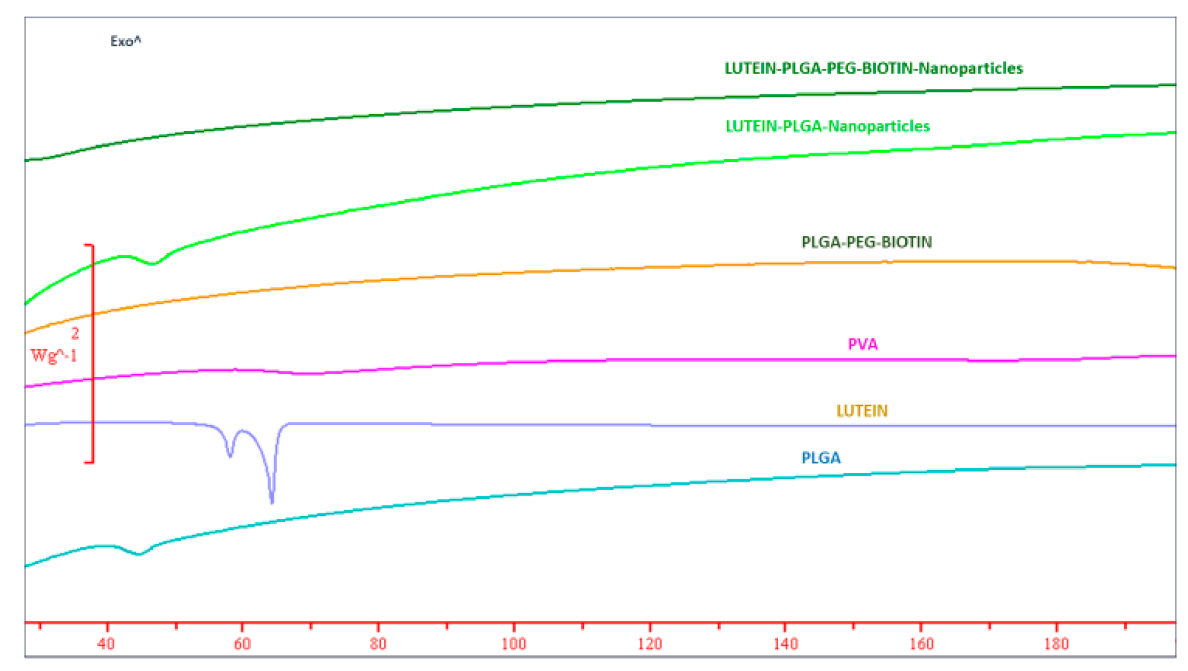

Figure 3. DSC thermograms of lutein-loaded PLGA-PEG-biotin nanoparticles, lutein-loaded PLGA nanoparticles, PLGA-PEG-biotin, PVA, lutein, and PLGA.

\subsection{FTIR}

FTIR spectroscopy was used to evaluate the surface chemistries of lutein, PVA, PLGA, PLGA-PEG-biotin, lutein-loaded PLGA, and PLGA-PEG-biotin nanoparticles (Figure 4). The broad transmittance band of lutein between 3588.88 and $3073.01 \mathrm{~cm}^{-1}$ corresponds to the $\mathrm{OH}$ stretching vibrations; it was absent in lutein-loaded PLGA and PLGA-PEG-biotin nanoparticles. In addition, characteristic C-H stretching bands were observed for lutein at 2958 and $2912 \mathrm{~cm}^{-1}$. A strong transmittance of lutein was also observed at $1620.15 \mathrm{~cm}^{-1}$ which was absent in the spectra of the lutein-loaded PLGA-PEG-biotin and PLGA nanoparticles. There was no obvious difference in the spectra of the polymers (PLGA and PLGA-PEG-biotin) and lutein-loaded polymeric nanoparticles. Results from FTIR confirm that the characteristic peaks of lutein were absent in the FTIR spectra of lutein-loaded polymeric nanoparticles. This could have been due to the strong interaction of lutein with the polymers which resulted in the absence of characteristic peaks. Similar results were observed 
for other nanoparticle systems [58]. Moreover, it is evident that the encapsulation of lutein did not result in any structural changes of polymers which might be attributed to either the small concentration of the drug or due to its bonding and non-bonding interactions with the surrounding matrix.

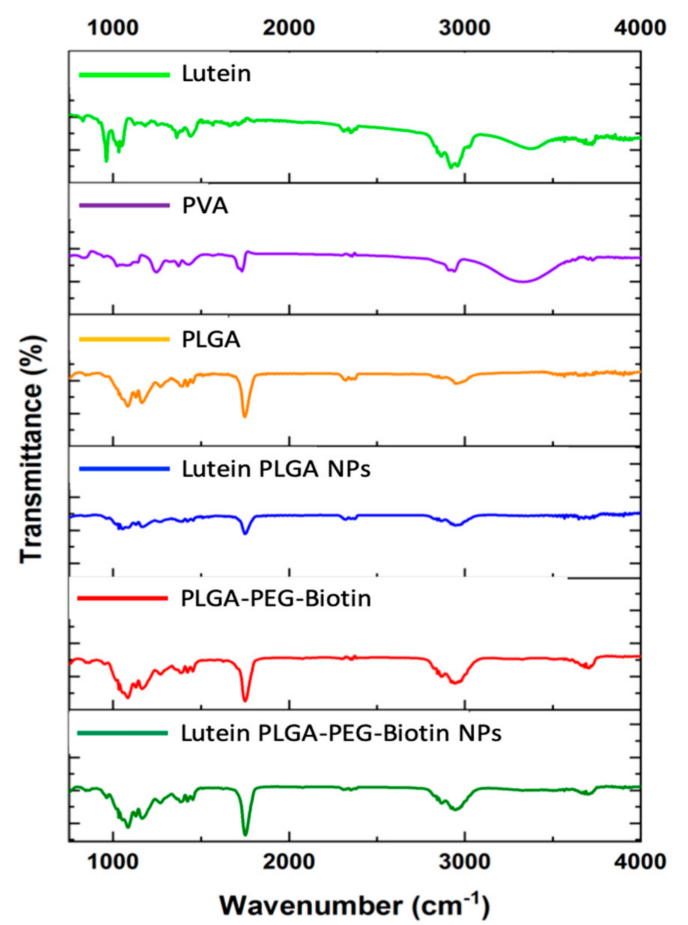

Figure 4. Fourier-transform infrared spectroscopy (FTIR) spectra of freeze-dried lutein-loaded polymeric nanoparticles, PLGA, PLGA-PEG-biotin, PVA, and lutein.

\subsection{In-Vitro Release Studies}

The in vitro release profile of lutein from PLGA and PLGA-PEG-biotin nanoparticles is provided in Figure 5. Release profiles revealed that the both the nano-formulations showed similar sustained release patterns with $100 \%$ of lutein released within $24 \mathrm{~h}$. Higher encapsulation of lutein in the polymers could have resulted in less space for polymer hydration and led to the slower release of lutein [59]. Overall, release studies validate the sustained/controlled release of drugs from polymeric nanoparticles.

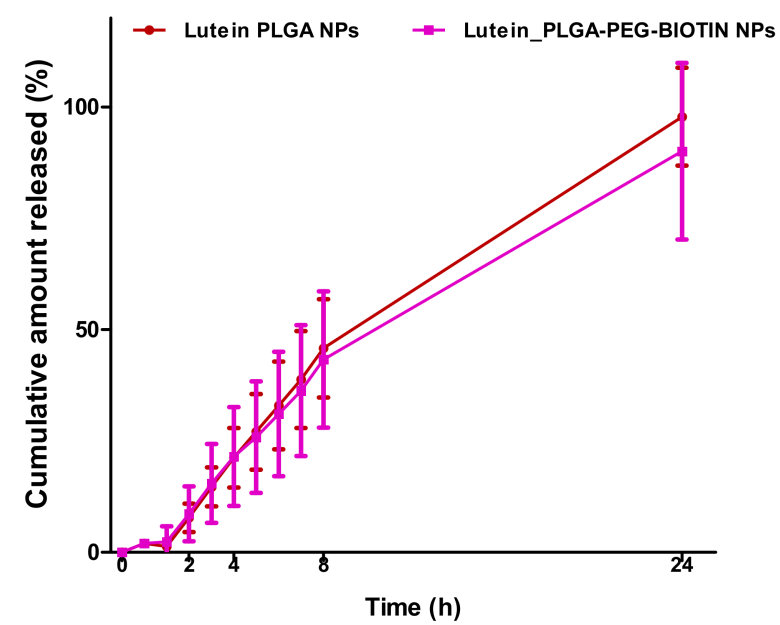

Figure 5. In-vitro release of lutein from lutein-loaded PLGA and PLGA-PEG-biotin NPs. Data are expressed as means \pm SDs $(n=3)$. 


\subsection{In-Vitro Cellular Uptake Studies}

In-vitro cellular uptake of lutein was determined in the ARPE-19 cell line to understand the intracellular localization and uptake of the biotin-decorated PLGA-PEG nanoparticles loaded with lutein compared to lutein-PLGA nanoparticles and lutein alone. These studies also helped to compare the uptake of the lutein nanoparticles within the cytoplasm of ARPE-19 cells. FACS and confocal microscopy were used as quantitative and qualitative analysis methods, respectively, to determine the cellular uptake.

\subsubsection{FACS Analysis}

FITC-labelled, lutein-loaded, biotin-decorated PLGA nanoparticles; PLGA nanoparticles; and lutein alone were incubated with ARPE-19 cells to determine in-vitro uptake at predetermined time points by using flow cytometry (mean FITC florescence intensity). Figure 6 depicts the time- dependent uptakes of FITC-labelled nanoparticles and lutein alone in ARPE-19 cells. Results show that at all time points, there was a significantly higher $(p<0.05)$ mean FITC florescence intensity with lutein-loaded, biotin-decorated nanoparticles and PLGA nanoparticles compared to lutein alone. In addition, it was also observed that at all time points intra cellular uptake of lutein-loaded biotin nanoparticles was numerically higher compared to lutein-loaded PLGA nanoparticles. However, the difference was not statistically significant $(p>0.05)$. Higher uptake with biotin-decorated nanoparticles could be attributed to the presence of a SMVT transporter on the surface of ARPE-19 cells. Results obtained in the study are consistent with other studies evaluating time-dependent uptake of biotinylated nanoparticles for targeted drug delivery $[27,56]$.

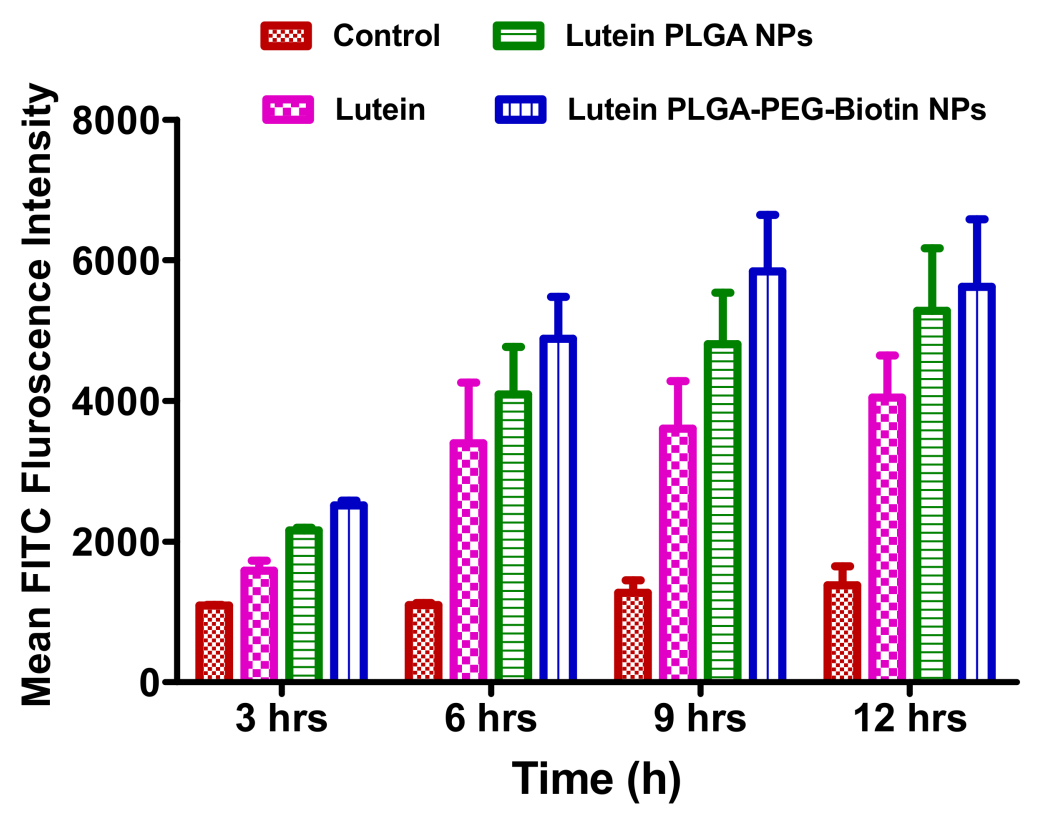

Figure 6. FACS analysis of control, lutein, and lutein-loaded polymeric nanoparticles (PLGA and PLGA-PEG-biotin) for 3, 6, 9, and $12 \mathrm{~h}$ in ARPE-19 cells. Data are expressed as means \pm SEMs ( $=3$ ).

\subsubsection{Confocal Microscopy}

In-vitro cellular uptake of FITC labelled lutein nanoparticles (PLGA and PLGA-PEG-biotin) and FITC-labelled lutein was performed using confocal laser scanning microscopy for qualitative analysis of lutein uptake by ARPE-19 cells. At the end of each time point the cells were washed, fixed, stained with DAPI, and mounted on a slide for visual observation for confocal microscopy. Figures 7 and 8 depict the in-vitro uptake of FITC-labelled lutein nanoparticles and FITC-labelled lutein at $6 \mathrm{~h}$ and $12 \mathrm{~h}$, respectively. It can be observed clearly that the green fluorescence for FITC 
increased in all the treatment groups with time. It is also interesting to note that at all timepoints, the fluorescence in the cells treated with FITC-labelled, lutein-loaded polymeric nanoparticles (PLGA and PLGA-PEG-biotin) was higher compared to FITC-labelled lutein. These results are well corroborated with the flow cytometry results. This could mean that biotin-decorated lutein nanoparticles and lutein PLGA nanoparticles are well absorbed via the lipid bilayer of ARPE-19 cells as compared to the lutein alone. Thus, the rate of internalization for lutein nanoparticles (PLGA and PLGA-PEG-biotin) into the cytoplasm and nuclei was higher compared to lutein alone. In addition, at 6 and $12 \mathrm{~h}$ timepoints, stronger fluorescence was observed with lutein-loaded PLGA-PEG-biotin nanoparticles compared to lutein-loaded PLGA nanoparticles. The higher uptake with biotin-decorated nanoparticles could be attributed to the SMVT transporter mediated uptake in ARPE-19 cells. Higher expression of biotin transporters on the surface of ARPE-19 cells resulted in higher uptake of lutein compared to other treatment groups.

FITC
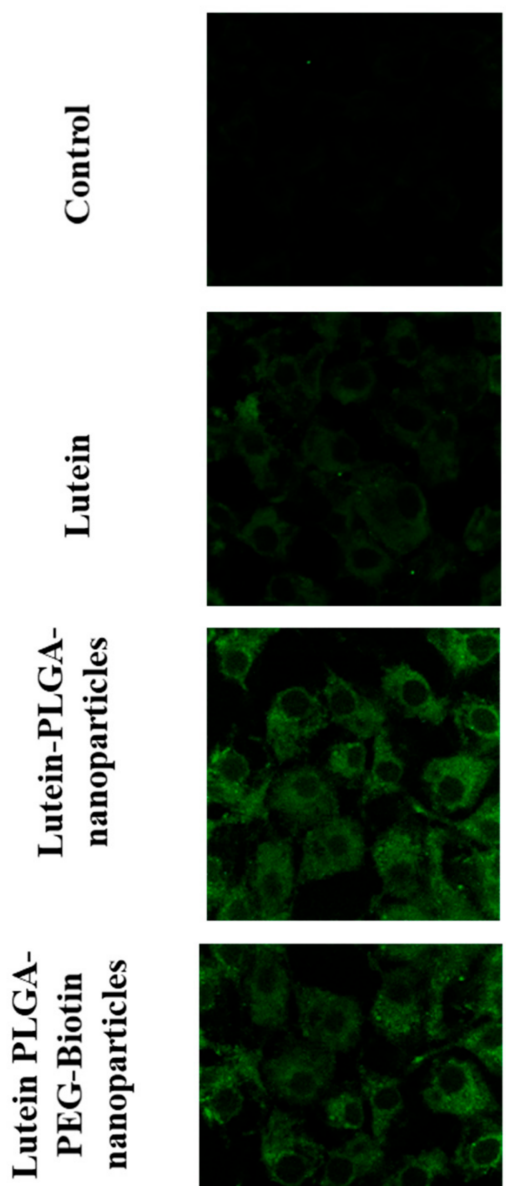

DAPI
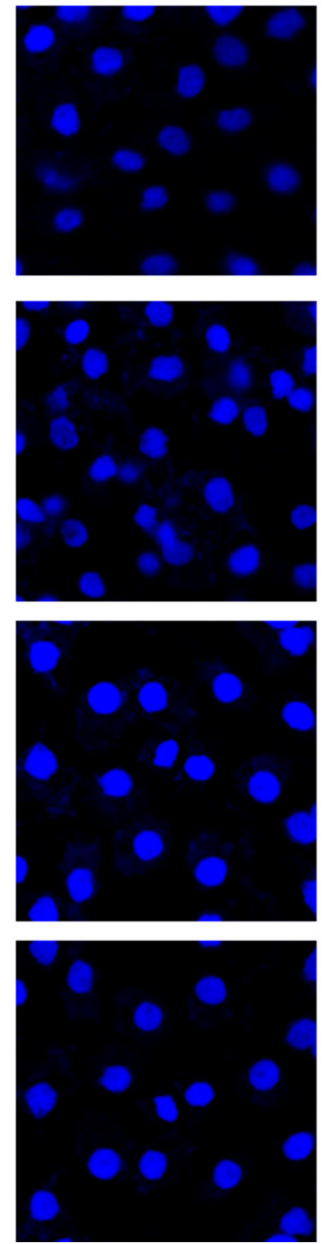

Merge
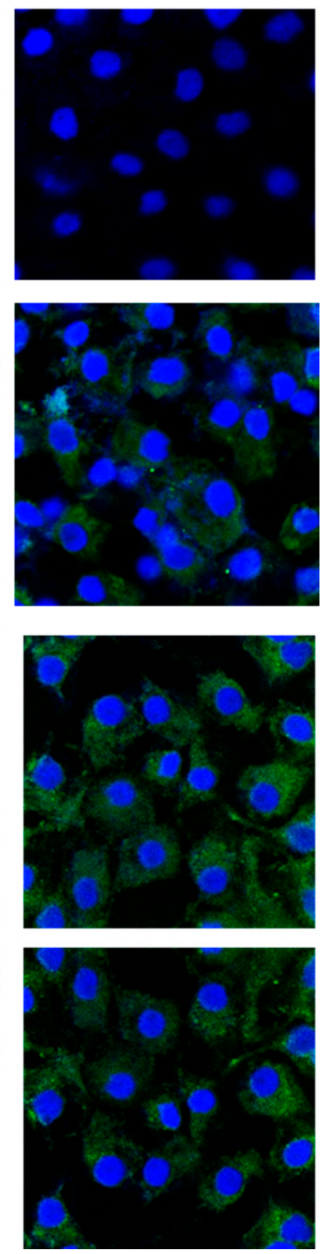

Figure 7. Confocal laser scanning microscopy images of FITC-labelled lutein and FITC-labelled lutein polymeric nanoparticles (PLGA and PLGA-PEG-biotin) at $6 \mathrm{~h}$ in ARPE-19 cells. 

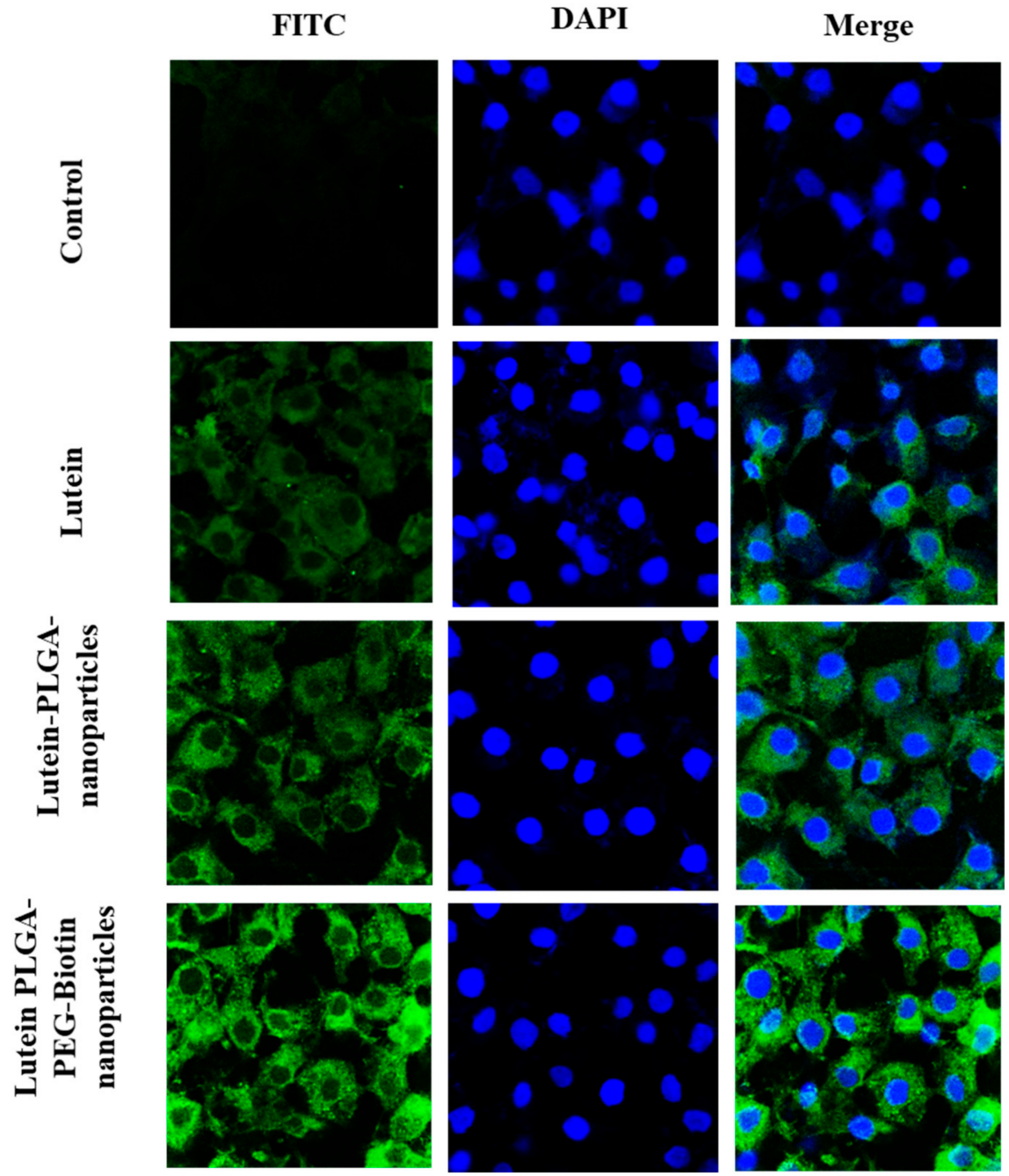

Figure 8. Confocal laser scanning microscopy images of FITC-labelled lutein and FITC-labelled lutein polymeric nanoparticles (PLGA and PLGA-PEG-biotin) at $12 \mathrm{~h}$ in ARPE-19 cells.

\subsection{In-Vitro Cytotoxicity Studies}

Figure 9 shows the cell viability (\%) of ARPE-19 cells when treated with increasing concentrations of lutein-loaded polymeric nanoparticles and lutein alone. Lutein and lutein-loaded polymeric nanoparticles did not exhibit any significant cytotoxicity at 10,20, and $50 \mu \mathrm{g} / \mathrm{mL}$ concentrations, proving that these nano-formulations are safe, effective, and non-toxic. Conjugates of biotin to PLGA nanoparticles did not result in any signs of toxicity and they were equivalent to lutein alone. 


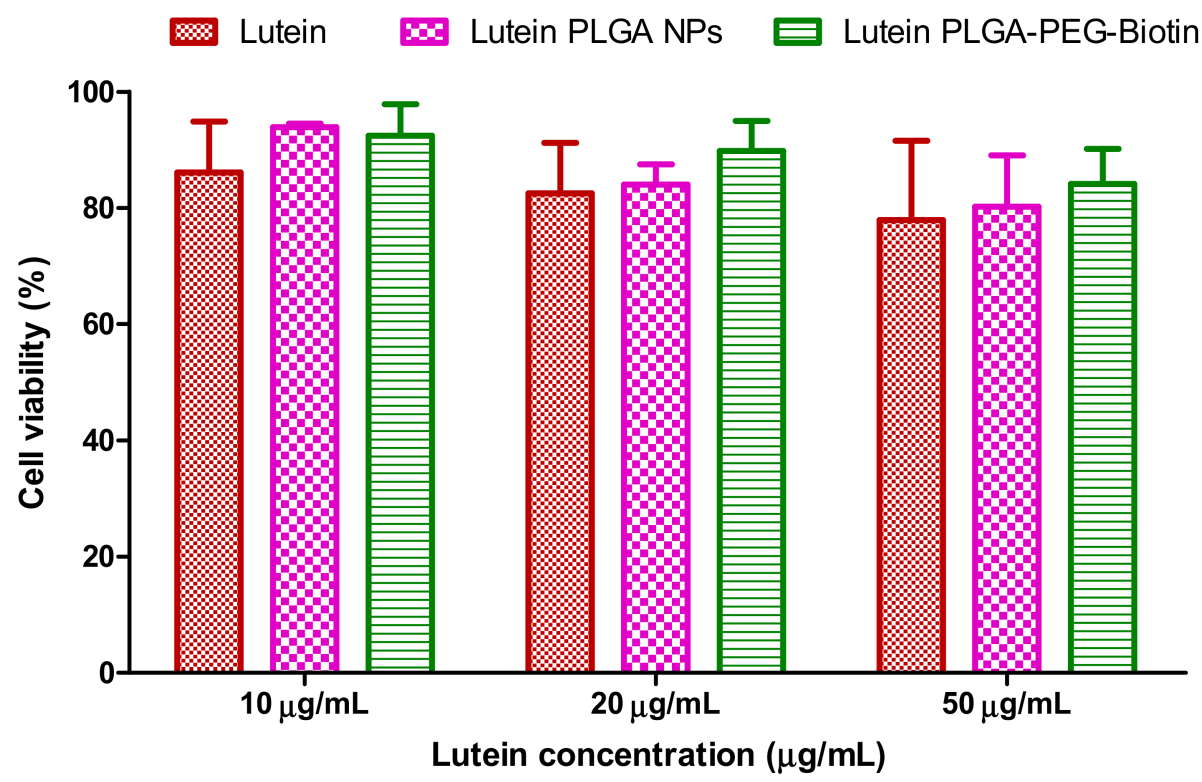

Figure 9. Cell viability (\%) of ARPE-19 cells when treated with increasing concentrations of lutein and lutein-loaded polymeric nanoparticles.

\section{Conclusions}

In conclusion, we have successfully developed and characterized lutein-loaded, biotin-decorated polymeric nanoparticles. The obtained nanoparticles possessed particle sizes of $<250 \mathrm{~nm}$ with narrow size distributions. Moreover, the biotin targeted nanoparticles showed higher encapsulation efficiency and drug loading. In-vitro cellular uptake studies revealed that biotin-decorated nanoparticles exhibited higher uptake of lutein compared to PLGA nanoparticles and lutein alone. In vitro cytotoxicity results confirmed that the nanoparticles showed higher cell viability compared to lutein alone. Collectively, we have found that the biotin-conjugated nanoparticles may be an appropriate formulation for targeted drug delivery in the treatment of AMD and other retinal diseases. However, these results are preliminary and should be confirmed by evaluating the efficacy, safety, and pharmacokinetics in pre-clinical models.

Author Contributions: Conceptualization, J.R. and P.K.B.; methodology, P.K.B., M.S., M.P., and V.G.; software, P.K.B. and V.G.; formal analysis, P.K.B.; investigation, J.R.; resources, J.R.; data curation, P.K.B. and V.G.; writing - original draft preparation, P.K.B.; writing—review and editing, J.R. and B.A.C.; supervision, J.R. and B.A.C.; funding acquisition, J.R. All authors have read and agreed to the published version of the manuscript.

Funding: This research received no external funding.

Acknowledgments: The authors would like to thank Joint School of Nanoscience and Nanoengineering (Greensboro, NC, USA) for providing access to Malvern Zetasizer.

Conflicts of Interest: All authors declare no conflict of interest.

\section{References}

1. Gaudana, R.; Jwala, J.; Boddu, S.H.; Mitra, A.K. Recent perspectives in ocular drug delivery. Pharm. Res. 2008, 26, 1197. [CrossRef] [PubMed]

2. Gaudana, R.; Ananthula, H.K.; Parenky, A.; Mitra, A.K. Ocular Drug Delivery. AAPS J. 2010, 12, 348-360. [CrossRef] [PubMed]

3. Nayak, K.; Misra, M. A review on recent drug delivery systems for posterior segment of eye. Biomed. Pharm. 2018, 107, 1564-1582. [CrossRef] [PubMed]

4. Chen, H. Recent developments in ocular drug delivery. J. Drug Target. 2015, 23, 597-604. [CrossRef] [PubMed] 
5. Keenan, T.D.; Vitale, S.; Agrón, E.; Domalpally, A.; Antoszyk, A.N.; Elman, M.J.; Clemons, T.E.; Chew, E.Y.; Age-Related Eye Disease Study 2 Research Group. AREDS2 Research Group Visual Acuity Outcomes after Anti-Vascular Endothelial Growth Factor Treatment for Neovascular Age-Related Macular Degeneration. Ophthalmol. Retin. 2020, 4, 3-12. [CrossRef] [PubMed]

6. Ma, L.; Yan, S.-F.; Huang, Y.-M.; Lu, X.-R.; Qian, F.; Pang, H.-L.; Xu, X.-R.; Zou, Z.; Dong, P.-C.; Xiao, X.; et al. Effect of Lutein and Zeaxanthin on Macular Pigment and Visual Function in Patients with Early Age-related Macular Degeneration. Ophthalmology 2012, 119, 2290-2297. [CrossRef] [PubMed]

7. Richer, S.; Stiles, W.; Statkute, L.; Pulido, J.; Frankowski, J.; Rudy, D.; Pei, K.; Tsipursky, M.; Nyland, J. Double-masked, placebo-controlled, randomized trial of lutein and antioxidant supplementation in the intervention of atrophic age-related macular degeneration: The Veterans LAST study (Lutein Antioxidant Supplementation Trial). Optom. J. Am. Optom. Assoc. 2004, 75, 216-229. [CrossRef]

8. De Jong, P.T. Age-Related Macular Degeneration. N. Engl. J. Med. 2006, 355, 1474-1485. [CrossRef]

9. Wu, J.; Cho, E.; Willett, W.C.; Sastry, S.M.; Schaumberg, D.A. Intakes of Lutein, Zeaxanthin, and Other Carotenoids and Age-Related Macular Degeneration During 2 Decades of Prospective Follow-up. JAMA Ophthalmol. 2015, 133, 1415-1424. [CrossRef]

10. Hu, D.; Lin, C.; Liu, L.; Li, S.; Zhao, Y. Preparation, characterization, and in vitro release investigation of lutein/zein nanoparticles via solution enhanced dispersion by supercritical fluids. J. Food Eng. 2012, 109, 545-552. [CrossRef]

11. Li, S.-Y.; Fu, Z.; Ma, H.; Jang, W.-C.; So, K.-F.; Wong, D.; Lo, A.C.Y. Effect of Lutein on Retinal Neurons and Oxidative Stress in a Model of Acute Retinal Ischemia/Reperfusion. Investig. Opthalmol. Vis. Sci. 2009, 50, 836-843. [CrossRef] [PubMed]

12. Moschos, M.M.; Dettoraki, M.; Tsatsos, M.; Kitsos, G.; Kalogeropoulos, C. Effect of carotenoids dietary supplementation on macular function in diabetic patients. Eye Vis. 2017, 4, 23. [CrossRef] [PubMed]

13. Allison, G.S.; Draper, C.S.; Soekamto, C.; Gong, X.M.; Rubin, L.P. Lutein Protects the Retinal Pigment Epithelium Against Hypoxic and Oxidative Stress: In Vitro Studies. FASEB J. 2016, 30, 2-5.

14. Gong, X.; Draper, C.S.; Allison, G.S.; Marisiddaiah, R.; Rubin, L.P. Effects of the Macular Carotenoid Lutein in Human Retinal Pigment Epithelial Cells. Antioxidants 2017, 6, 100. [CrossRef] [PubMed]

15. Ozawa, Y.; Sasaki, M.; Takahashi, N.; Kamoshita, M.; Miyake, S.; Tsubota, K. Neuroprotective Effects of Lutein in the Retina. Curr. Pharm. Des. 2012, 18, 51-56. [CrossRef]

16. Lutein. 2020. Available online: https://www.drugbank.ca/drugs/DB00137 (accessed on 31 May 2020).

17. Bachu, R.D.; Chowdhury, P.; Al-Saedi, Z.H.F.; Karla, P.K.; Boddu, S.H. Ocular Drug Delivery Barriers-Role of Nanocarriers in the Treatment of Anterior Segment Ocular Diseases. Pharmaceutics 2018, 10, 28. [CrossRef]

18. Kiernan, D.F.; Lim, J.I. Topical Drug Delivery for Posterior Segment Disease, Retin. Available online: https://retinatoday.com/pdfs/0510RT_Feature_Lim_Mosh.pdf (accessed on 24 July 2020).

19. Cholkar, K.; Ray, A.; Agrahari, V.; Pal, D.; Mitra, A.K. Transporters and receptors in the anterior segment of the eye. In Ocular Transporters and Receptors; Elsevier: Amsterdam, The Netherlands, 2013; pp. 115-168.

20. Patel, A.; Gokulgandhi, M.; Khurana, V.; Mitra, A.K. 5-Transporters and Receptors in the Posterior Segment of the Eye; Woodhead Publishing: Cambridge, UK, 2013; pp. 169-205.

21. Dey, S.; Mitra, A.K. Transporters and receptors in ocular drug delivery: Opportunities and challenges. Expert Opin. Drug Deliv. 2005, 2, 201-204. [CrossRef]

22. Boddu, S.H.; Nesamony, J. Utility of transporter/receptor(s) in drug delivery to the eye. World J. Pharmacol. 2013, 2, 1-17. [CrossRef]

23. Vadlapudi, A.D.; Vadlapatla, R.K.; Pal, D.; Mitra, A.K. Functional and Molecular Aspects of Biotin Uptake via SMVT in Human Corneal Epithelial (HCEC) and Retinal Pigment Epithelial (D407) Cells. AAPS J. 2012, 14, 832-842. [CrossRef]

24. Singh, Y.; Viswanadham, K.D.R.; Jajoriya, A.K.; Meher, J.G.; Raval, K.; Jaiswal, S.; Dewangan, J.; Bora, H.K.; Rath, S.K.; Lal, J.; et al. Click Biotinylation of PLGA Template for Biotin Receptor Oriented Delivery of Doxorubicin Hydrochloride in 4T1 Cell-Induced Breast Cancer. Mol. Pharm. 2017, 14, 2749-2765. [CrossRef]

25. Mehdizadeh, M.; Rouhani, H.; Sepehri, N.; Varshochian, R.; Ghahremani, M.H.; Amini, M.; Gharghabi, M.; Ostad, S.N.; Atyabi, F.; Baharian, A.; et al. Biotin decorated PLGA nanoparticles containing SN-38 designed for cancer therapy. Artif. Cells Nanomed. Biotechnol. 2016, 45, 1-10. [CrossRef] [PubMed] 
26. Luo, J.; Meng, X.; Su, J.; Ma, H.; Wang, W.; Fang, L.; Zheng, H.; Qin, Y.; Chen, T. Biotin-Modified Polylactic-co-Glycolic Acid Nanoparticles with Improved Antiproliferative Activity of 15,16-Dihydrotanshinone I in Human Cervical Cancer Cells. J. Agric. Food Chem. 2018, 66, 9219-9230. [CrossRef] [PubMed]

27. Joseph, A.; Wood, T.; Chen, C.-C.; Corry, K.; Snyder, J.M.; Juul, S.E.; Parikh, P.; Nance, E. Curcumin-loaded polymeric nanoparticles for neuroprotection in neonatal rats with hypoxic-ischemic encephalopathy. Nano Res. 2018, 11, 5670-5688. [CrossRef]

28. El-Say, K.M.; El-Sawy, H. Polymeric nanoparticles: Promising platform for drug delivery. Int. J. Pharm. 2017, 528, 675-691. [CrossRef]

29. Crucho, C.I.C.; Barros, M.T. Polymeric nanoparticles: A study on the preparation variables and characterization methods. Mater. Sci. Eng. C 2017, 80, 771-784. [CrossRef]

30. Kumari, A.; Yadav, S.K.; Yadav, S.C. Biodegradable polymeric nanoparticles based drug delivery systems. Colloids Surf. B Biointerfaces 2010, 75, 1-18. [CrossRef]

31. Khan, I.; Saeed, K.; Khan, I. Nanoparticles: Properties, applications and toxicities. Arab. J. Chem. 2019, 12, 908-931. [CrossRef]

32. Bahrami, B.; Hojjat-Farsangi, M.; Mohammadi, H.; Anvari, E.; Ghalamfarsa, G.; Yousefi, M.; Jadidi-Niaragh, F. Nanoparticles and targeted drug delivery in cancer therapy. Immunol. Lett. 2017, 190, 64-83. [CrossRef]

33. Banik, B.L.; Fattahi, P.; Brown, J.L. Polymeric nanoparticles: The future of nanomedicine. Wiley Interdiscip. Rev. Nanomed. Nanobiotechnol. 2015, 8, 271-299. [CrossRef]

34. Lim, C.; Kim, D.-W.; Sim, T.; Hoang, N.H.; Lee, J.W.; Lee, E.S.; Youn, Y.S.; Oh, K.T. Preparation and characterization of a lutein loading nanoemulsion system for ophthalmic eye drops. J. Drug Deliv. Sci. Technol. 2016, 36, 168-174. [CrossRef]

35. Tan, T.B.; Yussof, N.S.; Abas, F.; Mirhosseini, H.; Nehdi, I.A.; Tan, C.P. Stability evaluation of lutein nanodispersions prepared via solvent displacement method: The effect of emulsifiers with different stabilizing mechanisms. Food Chem. 2016, 205, 155-162. [CrossRef] [PubMed]

36. Muhoza, B.; Zhang, Y.; Xia, S.; Cai, J.; Zhang, X.; Su, J. Improved stability and controlled release of lutein-loaded micelles based on glycosylated casein via Maillard reaction. J. Funct. Foods 2018, 45, 1-9. [CrossRef]

37. Mitri, K.; Shegokar, R.; Gohla, S.; Anselmi, C.; Müller, R.H. Lutein nanocrystals as antioxidant formulation for oral and dermal delivery. Int. J. Pharm. 2011, 420, 141-146. [CrossRef] [PubMed]

38. Steiner, B.; McClements, D.J.; Davidov-Pardo, G. Encapsulation systems for lutein: A review. Trends Food Sci. Technol. 2018, 82, 71-81. [CrossRef]

39. Silva, J.; Geiss, J.M.T.; Oliveira, S.M.; Brum, E.D.S.; Sagae, S.C.; Becker, D.; Leimann, F.V.; Ineu, R.P.; Guerra, G.P.; Gonçalves, O.H. Nanoencapsulation of lutein and its effect on mice's declarative memory. Mater. Sci. Eng. C 2017, 76, 1005-1011. [CrossRef] [PubMed]

40. Brum, A.A.S.; Dos Santos, P.P.; Da Silva, M.M.; Paese, K.; Guterres, S.S.; Costa, T.M.; Pohlmann, A.R.; Jablonski, A.; Flôres, S.H.; Rios, A.D.O. Lutein-loaded lipid-core nanocapsules: Physicochemical characterization and stability evaluation. Colloids Surf. A Physicochem. Eng. Asp. 2017, 522, 477-484. [CrossRef]

41. Jwala, J.; Boddu, S.H.; Shah, S.; Sirimulla, S.; Pal, D.; Mitra, A.K. Ocular Sustained Release Nanoparticles Containing Stereoisomeric Dipeptide Prodrugs of Acyclovir. J. Ocul. Pharmacol. Ther. 2011, 27, 163-172. [CrossRef]

42. Boddu, S.H.; Vaishya, R.; Jwala, J.; Vadlapudi, A.; Pal, D.; Mitra, A.K. Preparation and Characterization of Folate Conjugated Nanoparticles of Doxorubicin using Plga-Peg-Fol Polymer. Med. Chem. 2012, 2, 068-075. [CrossRef]

43. Liu, R.; Sun, M.; Liu, X.; Fan, A.; Wang, Z.; Zhao, Y. Interplay of stimuli-responsiveness, drug loading and release for a surface-engineered dendrimer delivery system. Int. J. Pharm. 2014, 462, 103-107. [CrossRef]

44. Chaganti, L.K.; Venkatakrishnan, N.; Bose, K. An efficient method for FITC labelling of proteins using tandem affinity purification. Biosci. Rep. 2018, 38. [CrossRef]

45. Michlewska, S.; Kubczak, M.; Maroto-Díaz, M.; Del Olmo, N.S.; Ortega, P.; Shcharbin, D.; Gómez, R.; De La Mata, F.J.; Ionov, M.; Bryszewska, M. Synthesis and Characterization of FITC Labelled Ruthenium Dendrimer as a Prospective Anticancer Drug. Biomolecules 2019, 9, 411. [CrossRef] [PubMed] 
46. Damgé, C.; Maincent, P.; Ubrich, N. Oral delivery of insulin associated to polymeric nanoparticles in diabetic rats. J. Control. Release 2007, 117, 163-170. [CrossRef] [PubMed]

47. Mandal, A.; Cholkar, K.; Khurana, V.; Shah, A.; Agrahari, V.; Bisht, R.; Pal, D.; Mitra, A.K. Topical Formulation of Self-Assembled Antiviral Prodrug Nanomicelles for Targeted Retinal Delivery. Mol. Pharm. 2017, 14, 2056-2069. [CrossRef] [PubMed]

48. Javidfar, S.; Pilehvar-Soltanahmadi, Y.; Farajzadeh, R.; Lotfi-Attari, J.; Shafiei-Irannejad, V.; Hashemi, M.; Zarghami, N. The inhibitory effects of nano-encapsulated metformin on growth and hTERT expression in breast cancer cells. J. Drug Deliv. Sci. Technol. 2018, 43, 19-26. [CrossRef]

49. Firouzi-Amandi, A.; Dadashpour, M.; Nouri, M.; Zarghami, N.; Serati-Nouri, H.; Jafari-Gharabaghlou, D.; Karzar, B.H.; Mellatyar, H.; Aghebati-Maleki, L.; Babaloo, Z.; et al. Chrysin-nanoencapsulated PLGA-PEG for macrophage repolarization: Possible application in tissue regeneration. Biomed. Pharm. 2018, 105, 773-780. [CrossRef]

50. USFDA, Inactive Ingredient Search for Approved Drug Products, (n.d.). Available online: https://www. accessdata.fda.gov/scripts/cder/iig/index.cfm (accessed on 28 July 2019).

51. Bolla, P.K.; Kalhapure, R.S.; Rodriguez, V.A.; Ramos, D.V.; Dahl, A.; Renukuntla, J. Preparation of solid lipid nanoparticles of furosemide-silver complex and evaluation of antibacterial activity. J. Drug Deliv. Sci. Technol. 2019, 49, 6-13. [CrossRef]

52. Bolla, P.K.; Meraz, C.A.; Rodriguez, V.A.; Deaguero, I.G.; Singh, M.; Yellepeddi, V.K.; Renukuntla, J. Clotrimazole Loaded Ufosomes for Topical Delivery: Formulation Development and In-Vitro Studies. Molecules 2019, 24, 3139. [CrossRef]

53. Rodriguez, V.A.; Bolla, P.K.; Kalhapure, R.S.; Boddu, S.H.; Neupane, R.; Franco, J.; Renukuntla, J. Preparation and Characterization of Furosemide-Silver Complex Loaded Chitosan Nanoparticles. Processes 2019, 7, 206. [CrossRef]

54. Morissette, S.L. High-throughput crystallization: Polymorphs, salts, co-crystals and solvates of pharmaceutical solids. Adv. Drug Deliv. Rev. 2004, 56, 275-300. [CrossRef]

55. Musumeci, T.; Serapide, M.; Pellitteri, R.; Dalpiaz, A.; Ferraro, L.; Magro, R.D.; Bonaccorso, A.; Carbone, C.; Veiga, F.; Sancini, G.; et al. Oxcarbazepine free or loaded PLGA nanoparticles as effective intranasal approach to control epileptic seizures in rodents. Eur. J. Pharm. Biopharm. 2018, 133, 309-320. [CrossRef]

56. Bragagni, M.; Gil-Alegre, M.E.; Mura, P.; Cirri, M.; Ghelardini, C.; Mannelli, L.D.C. Improving the therapeutic efficacy of prilocaine by PLGA microparticles: Preparation, characterization and in vivo evaluation. Int. J. Pharm. 2018, 547, 24-30. [CrossRef] [PubMed]

57. Ayoub, M.M.; Elantouny, N.G.; Elnahas, H.; Ghazy, F.E.-D.S. Injectable PLGA Adefovir microspheres; the way for long term therapy of chronic hepatitis-B. Eur. J. Pharm. Sci. 2018, 118, 24-31. [CrossRef] [PubMed]

58. Ahlawat, J.; Deemer, E.M.; Narayan, M. Chitosan Nanoparticles Rescue Rotenone-Mediated Cell Death. Materials 2019, 12, 1176. [CrossRef] [PubMed]

59. Kamaly, N.; Yameen, B.; Wu, J.; Farokhzad, O.C. Degradable Controlled-Release Polymers and Polymeric Nanoparticles: Mechanisms of Controlling Drug Release. Chem. Rev. 2016, 116, 2602-2663. [CrossRef] [PubMed]

(C) 2020 by the authors. Licensee MDPI, Basel, Switzerland. This article is an open access article distributed under the terms and conditions of the Creative Commons Attribution (CC BY) license (http://creativecommons.org/licenses/by/4.0/). 